\title{
DERLEME/REVIEW
}

\section{Ölüm iyiliği fenomeni}

\author{
Terminal lucidity phenomena \\ Mehmet Emin Demirkol ${ }^{1}$, Lut Tamam² \\ ${ }^{1}$ Samandağ Devlet Hastanesi, Hatay, Turkey \\ ${ }^{2}$ Çukurova Üniversitesi Tıp Fakültesi, Ruh Sağlığı ve Hastalıkları Anabilim Dalı, Adana, Turkey
}

\begin{abstract}
Unexpected symptom remission in psychiatric and neurologic disesases shortly before patients' death have been known since last 250 years but not received enough attention. This phenomenon is called terminal lucidity. Terminal lucidity can be experienced at patients with diagnosis of dementia, schizophrenia, brain abscess, brain tumour, stroke and mood disorders. Explanatory models about reasons and neurobiology of this phenomenon will contribute to develop new treatment strategies about mentioned diseases and to live last moments times before death better
\end{abstract}

Key words: Terminal lucidity, dementia, schizophrenia

\section{GİRİ̧̧}

Demans ve şizofreni başta olmak üzere, psikiyatrik ve nörolojik hastalıklarda ölümden dakikalar, saatler bazen günler, haftalar öncesinde hastalık şiddetinde beklenmedik şekilde azalma, semptomlarda iyileşme görülmesi Hipokrat, Plutarkos, Galen, İbnisina gibi dönemlerinin saygın bilim insanları tarafindan belirlenmiş ve son 250 yıldır bu durumu açıklayan olgu örnekleri literatürde yer almıştır ${ }^{1}$. Geçmiş yıllarda gözlemlenen kronik psikiyatrik hastaların sadece $\% 2$ 'sinin ruhsal durumlarının kötüye gittiğini, \%63'ünün aynı kaldığını, \%22'sinin ise daha iyiye gittiğini belirtilmiştir ${ }^{2}$. Bu zihin açıklığı, aydınlanma dönemi belki de tanık olmadıkları için zaman zaman tıp hekimleri tarafından göz ardı edilmiş, felsefe ile uğraşan kişilerin dikkatini çekmiştir ${ }^{2,3}$.

Geçmiş literatürden elde edebildiğimiz verilere göre terminal lucidity prevalansı hakkında yorum yapmak

\section{Öz}

Psikiyatrik ve nörolojik hastalıklarda, hastalığın genel seyrinin aksine ölümden kısa süre önce zihin açıklığı yaşanması, hastalık semptomlarının iyileşme göstermesi son 250 yildır literatürde yer almasına rağmen yeteri kadar ilgi görmemiştir. İngilizce kaynaklarda 'terminal lucidity' olarak yer alan bu fenomen Türkçe'ye ölüm iyiliği olarak çevrilebilir. Ölüm iyiliği fenomeni; demans, şizofreni, beyin absesi, beyin tümörü, inme ve duygudurum bozukluklarında görülebilir. Bu fenomenin sebeplerinin, nörobiyolojisinin açıklı̆ga kavuşturulması, bahsedilen hastalıklar için yeni tedavi yöntemlerinin geliştirilmesine ve ölümden önceki son zamanların hastalar ve hasta yakınları açısından daha mutlu geçirilmesine katkıda bulunacaktır.

Anahtar kelimeler: Ölüm iyiliği, demans, şizofreni

güçtür. Yapılan araştırmalar 2030 yılında her 10 ölümden sadece birinin evde gerçekleşeceğini göstermektedir. $\mathrm{Bu}$ durum ölüm iyiliği fenomeni sergileyen olgulara hekimler tarafindan daha fazla tanıklık edileceğini ve bu fenomenin daha fazla araştırılacağını göstermektedir ${ }^{4}$.

Ölüm iyiliği fenomeninin nörobiyolojisinin, nörokimyasal altyapısının aydınlatılması bu fenomenin görüldüğü hastalıklardaki iyilik hali dönemlerinin uzamasına, kronik hastalık döneminde hasta ve aile bireylerinin çektiği acıların hafiflemesine ve ölümden önceki son dönemlerin daha huzurlu geçirilmesine yardımcı olacaktır.

\section{TARİHÇE}

Hipokrat zamanından bu yana bu fenomene dikkat çekilmiş olsa bile ölüm iyiliği fenomeni ile ilgili ulaşılabilen kayıtlar 1800'lü yıllardan önce ve 1800 ’lü

Yazışma Adresi/Address for Correspondence: Dr. Mehmet Emir Demirkol, Samandağ Devlet Hastanesi, Hatay, Turkey. E-mail: emindemirkol@gmail.com

Geliş tarihi/Received: 24.03.2016 Kabul tarihi/Accepted: 02.05.2016 
yıllarda hastaya bakımveren aile bireyinin ya da bakım hemşiresinin gözlemine dayanmaktaydı. İlerleyen yıllarla birlikte hekimlerin de gözlemlerine dayanan olgu örnekleri literatürde yer almaya başlamışıtır ${ }^{1}$.

Ulaşılabilen kaynaklara göre, 19. yüzyıldan önce 16, 19. yüzyılda 46, 20. Yüzyılda 14 olgu örneği bulunmaktadır. Özellikle 19. yüzyıldan önce elde edilen kayıtlarda, hastalık siniflama sistemleri günümüzden oldukça farklı olup, tanılar genelde mani, melankoli şeklindedir. 1900'lü yıllarda ölüm iyiliği fenomeni ile ilgili yayınlanan tıbbi makale sayısında bir önceki yüzyıla göre azalma olmakla birlikte bu konu üzerinde daha çok felsefe ile ilgilenen kişiler çalışmıştır ${ }^{5}$.

1975 y1lında Turetskaia ve Romanenko tarafindan 3 kronik şizofren hasta ile ilgili yayınlanan makaleye kadar bu konuya tıp dünyasının yeteri kadar ilgi gösterdiği söylenemez ${ }^{6}$. Rusça yayınlanan ve konunun tekrar gündeme gelmesini sağlayan bu makaleden sonra Amerika Birleşik Devletleri ve Avrupa'da klinisyenler bu konuya dikkat çekmiş ve makaleler yayınlamışlardır. 2000'li yıllarda itibaren ise özellikle Michael Nahm ve Bruce Greyson isimli klinisyenler, ölüm iyiliği fenomeni ile ilgili verileri toplayıp, bu konunun sebepleri, nörobiyolojisi ile ilgili araştırmalar yapmışlardır.

\section{ETYOLOJİ}

Ölüm iyiliği ile ilgili olgua örnekleri, Alzheimer demansı ve şizofreni başta olmak üzere beyin absesi, beyin tümörü, menenjit, inme ve duygudurum bozukluğu tanısıyla izlenen hastaların öykülerine dayanmaktadır. Hastaların, yaşamlarının son dönemlerinde yaşadıkları bu zihinsel berraklık dönemini tek bir mekanizmayla açıklamak mümkün görünmemektedir².

Bu fenomeni açıklayabilmek için bazı hipotezler öne sürülmüştür. Örneğin kronik hastalığa bağlı kaşeksi yaşayan hastalarda beyin dokusu da küçülmekte ve kafa içi yer kaplayan kitleye bağlı kafa içi basınç azalmaktadır. Basınç azalmasına bağlı ruhsal belirtilerin şiddetinde bir hafifleme görülebilmektedir.

Bir diğer hipotez ise vital bulguların yavaşlaması ile hastalık şiddetinin azalması ve semptomların daha ılımlı hale gelmesidir. Bu hipotez; sanrı, varsanı, saldırganlık gibi renkli klinik görünümü olan şizofreni hastalarının hayatlarının son dönemlerinde yaşadığı zihin açıklığını ve hastalık belirtilerinin şiddetinin azalmasını açıklamak için öne sürülmüştür ${ }^{2}$.

Bir varsayıma göre ise anatomik yapısı korunmuş ya da az miktarda hasar görmüş beyin ölmeden önce panik düğmesine basılmışçasına kısa süreliğine de olsa eski işlevlerini kazanabilmektedir. Bu varsayım özellikle şizofreni hastalarındaki ölüm iyiliği fenomenini aç1klamak için öne sürülmüştür. Menenjit, Alzheimer demansı gibi beynin anatomik yapısına ciddi şekilde hasar veren hastalıklarda bu hipotezin geçerli olduğunu söylemek güçtür. Ayrıca günümüzde şizofreninin de beynin anatomik yapısında değişikliğe neden olduğu ( ventriküllerde genişleme, kortikal küçülme gibi) gösterilmiştir. Bu nedenle bu hipotezin geçerliliği tartışmaya açıktır ${ }^{1}$.

Baz1 klinisyenler ölümden önce yükselen vücut ısısının ölüm iyiliği fenomenine sebep olabileceğini öne sürmüştür. Bu duruma dayanak olarak da geçmişte bazı psikiyatrik hastalıkların tedavisi için vücut 1sısının yükseltilmesi yöntemini göstermişlerdir. 1883 y1lında Wagner-Jauregg streptokokal bir enfeksiyon olan erizipel tanısı alan bir hastanın psikotik belirtilerinde düzelme saptamıştır. Bu gözlemi üzerine çeşitli enfeksiyöz ajanlar1 hastalara enjekte ederek vücut 1sılarında yükselmeye neden olmuştur. Hastaların \%83’ünün psikiyatrik belirtilerinde düzelme saptayan WagnerJauregg sıtma aşısını paralitik demans tedavisinde kullanmış ve bu çalışması nedeniyle 1927 yılında Nobel Ödülü almaya hak kazanmıştır. WagnerJauregg’i takip eden araştırmacılar; sıcak banyosu, elektrik yardımıyla vücut isısının yükseltilmesi gibi yöntemlerle yüksek ateş tedavisini kullanmış ve nörosifilizin psikotik belirtilerinin yanısıra hastalığın serolojik ve elektroensefalografik bulgularında da düzelme elde etmişlerdir. Wagner-Jauregg yüksek ateş tedavisinin melankoli ve manide de etkili olacağını öne sürmüştür ancak diğer araştırmacılar tarafindan psikoz tedavisinde kullanılan yüksek ateș tedavisi olumlu sonuç vermemiştir ${ }^{5,9}$. Palop ve Savioz, Alzheimer hastalığının tamamıla geri dönüşümsüz nöron kaybına bağlı olmadığını belki de geri dönüşümlü şekilde moleküler düzeydeki değişimlere, sinyal döngülerine, sinaptik değişimlere bağlı olduğunu öne sürmüşlerdir. Bu geri dönüşümlü durumlar özellikle erken evre demans hastalarının yaşadığ1 ölüm iyiliği fenomenine açılık getirebilir'2,10,11. Ölüm iyiliği fenomeni ile ilgili bir diğer varsayım ise bu durumun Alzheimer demansinda ve beyin tümöründe ölümün habercisi 
olarak yorumlanması gerektiğidir ${ }^{1}$. Non-materyalistik yaklaşıma göre ölüm iyiliği fenomeninin açıklanmasında belki de bilinen -klasik- beyin fizyolojisinden daha geniş bir bakış açısı gerekmektedir. Hastaların ölümden önce yaşadığı bu aydınlanma ve bilinç dönemi beyinden bağımsız bir yaklaşım gerektiriyor olabilir ${ }^{1}$.

\section{TARİHSEL OLGU ÖRNEKLERİ}

Ölüm iyiliği ile ilgili bugüne kadar yayınlanan en dikkat çekici ve uç olgu 1896-1922 yılları arasında yaşayan Anna Katharina Ehmer diğer adıyla Kathe olgusudur. Bu olgu dönemin iki saygın bilim insanı Happich ve Wittneben tarafindan ayr1 ayr1 raporlanmıştır ${ }^{12,13}$. Kathe klinik kayıtlara göre tüberküloz tanısıyla takip edilen bir olgu olup, hayatının büyük kısmını bakımevinde geçirmiştir. Tüberküloza bağlı kemik tutulumu nedeniyle bir ayağ1 ampute edilmiştir. Hastalığ1 zamanla ilerleyip menenjite dolayısıyla beyin hasarına neden olmuştur. Beyin hasarına bağlı olarak konuşma yetisi hiçbir zaman gelişmeyen Kathe'nin, vaktini saatlerce bir noktaya sabit bakarak, yerinde duramaz şekilde hareket ederek, tıkınırcasına yemek yiyerek ve anlamsız şekilde çı̆̆lık atarak geçirdiği kayıtlarda belirtilmektedir. Yaşadığı dönemde, kaldığ1 akıl hastanesinin en ağır olgularından biri kabul edilen Kathe'nin, tüm yaşamı boyunca tek bir sözcük dahi konuşmamasına rağmen ölümünden 30 dakika önce kendiliğinden ölüm ve huzur hakkında şarkılar söylemeye başladığı, 30 dakika boyunca mantıklı bir biçimde bu şarkıyı mirıldandıktan sonra huzur içerisinde öldüğü gözlenmiştir. Kathe'yi takip eden hekim ve yardımcı sağlık personelleri bu durumu mucize olarak yorumlamışlardır ${ }^{14} .1975$ yılında Turetskaia ve Romanenko tarafindan yayınlanan, 20. yüzyılda ölüm iyiliği fenomenini tıp çevrelerinde tekrar gündeme getirmesi ile öncü nitelik taşıyan makalede ise 3 kronik şizofreni olgusundan bahsedilmektedir. Bu olgularından ilki, hayatının son 27 yllını tedaviye yanıt vermeyen kronik şizofreni tanısı ile geçiren ve 17 y1l boyunca katatonik postürde yaşayan hastadır. Ölümünden 45 gün önce şizofreni semptomlarında gerileme gözlenen olgunun, öldügüünde ruhsal açıdan neredeyse normal kabul edilecek düzeyde olduğu belirtilmektedir. Turetskaia ve Romanenko tarafindan yayınlanan ikinci olgu ise yaşamının 20 yılını akıl hastanelerinde geçirmiş olup, mide kanserinden ölmeden yaklaşık 45 gün önce ruhsal işlevlerinde düzelme başlayan bir olgudur. Son olgu ise yine şizofreni tanısılla takip edilmekte olup belirgin iyilik hali göstermesi üzerine, yakınları tarafindan kaldığı akıl hastanesinden taburcu edilip son günlerini evde geçiren bir hastadir $^{3}$. Turetskaia ve Romanenko tarafindan raporlanan her 3 olgunun ortak özelliği uzun yıllar boyunca akıl hastanesinde veya bakımevinde kalıp, tedavi girişimlerine yanıtsız kalmalarıdır. Yaşamlarının son dönemlerinde bu 3 hasta, Kathe olgusundan farklı olarak 30 dakika gibi kısa bir süre değil yaklaşık 45 gün kadar mental iyilik hali göstermişlerdir. Bu durum ölüm iyiliği fenomeni için birden fazla (belki de her hastalık için ayrı) açıklayıcı model olması gerektiğini düşündürmektedir ${ }^{3,14}$.

Nahm ve arkadaşları. tarafindan bildirilen bir olgu örneğinde Alzheimer tanısı ile izlenen yaşlı bir kadın, yıllar boyunca ailesi ve yakınları ile konuşmamıs, iletişim kurmamıştır. Ölümünden bir hafta önce torunuyla konuşmaya başlayan kadın, ailenin diğer bireylerinin nasıl olduğunu sormuş ve torununa yaşamla ilgili önerilerde bulunmuştur ${ }^{2}$.

Leubuscher tarafindan 1846 yilında bildirilen olgu örneğinde kronik menenjit tanısılla akıl hastanesinde takip edilen bir kadının 1844-1846 yılları arasında birkaç kez özkıyım girişiminde bulunduğundan, kıyafetlerini yırttığından ve amaçsız şekilde etrafta dolandığından bahsedilir. Geçmişi tamamen unutan olgu 5 çocuğu olmasina rağmen çocuğu olmadığını iddia etmiş ve zaman içerisinde dış dünyaya karşı tamamen tepkisiz bir hal almıştır. 1846 Şubat'ında ölmeden önce vücut işlevleri zayıfladıkça -ilginç şekilde- ruhsal durumu düzelmeye başlamıştır. Belleği tümüyle tazelenen olgu, nerede olduğunun farkına varmış, kendisine bakımveren personele teşekkür etmiştir. Ölmeden önceki son dönemlerini tam olarak bilinçli şekilde geçirmiştir ${ }^{2,15}$.

Noyes inme atağı geçiren 91 yaşındaki bir kadın hastadan bahsettiği makalesinde, hastanın geçirdiği ataklar sonucunda hareket etme, mimik yapma ve konuşma yeteneğini tamamen kaybettiğinden bahsetmiştir. Ölümünden kısa süre önce kızının gözlemine göre gülümsemeye başlayan olgu, yardım almadan yatakta doğrularak oturmaya başlamış ve neşeli bir ses tonuyla ölmüş eşinin ismini söylemiştir. Bu beklenmedik ve şaşırtıcı hareketleri yaptıktan kısa süre sonra vefat eden olgu hakkında Osis ölüm döşeği fenomeni yaşamış olabileceğini ve ölen eşini görmüş olabileceğini belirtmiştir ${ }^{2,16,17}$.

Butzke tarafindan bildirilen ve klinik olarak günümüzde bipolar bozukluk tanısı alması olası bir olgu melankoli tanısıyla akıl hastanesine kabul 
edildikten sonra manik belirtiler göstermeye başlamıştır. Dört yıllık dönemi konfüze ve zihinsel açıdan sıkıntılı geçirdikten sonra ateşli bir hastalığa yakalanan olgu önerilen tedavi rejimlerini reddetmiştir. Vücut işlevleri kötüleştikçe zihinsel açıdan iyilik hali göstermeye başlamıştır. Eğitim düzeyini aşacak cümleler kuran olgu, yakınlarının durumunu sormuş ve ölmeden kısa süre önce gözyaşları içinde tedaviyi reddettiği için pişmanlığını dile getirmiştir ${ }^{2,18}$.

\section{SONUÇ}

Ölüm iyiliği fenomeni uzun yıllardır bilinmesine rağmen, gerek hekimlerin yeteri kadar önem vermemesi, gerek tıbbi geçerliliği olan yeteri kadar kanit sunulamamasi, gerek de seyri sirasinda ortaya çıtığı hastalıkların bilinen fizyopatolojileri ile açılanamaması nedeniyle günümüze kadar yeteri kadar ilgi görmemiştir. Ölümden önce görülen bu aydinlanma fenomenine bugüne kadar bakımverenler, hasta yakınları tarafindan dini, filozofik anlamlar yüklenmesi hekimlerin bu konuya imtina ile yaklaşmasına neden olmuştur. En ağır psikiyatrik, nörolojik hastalıklarda bile hastaların iç dünyasında hala akıl kırıntılarının olduğu ve ölümden önce hastalık perdesinin aralanarak bu akıl kırıntılarının yüzeye ulaştı̆̆ı çeşitli klinisyenler tarafindan öne sürülmüştür. $\mathrm{Bu}$ fenomen birçoklarına göre beynin hastaya son bir hoşçakal deme şansı tanımasıdır ${ }^{4}$. Materyalistik ve nonmateryalistik birçok açıklayıcı model geliştirilmeye çalışılsa da bugüne dek ölüm iyiliği fenomeni ile ilgili olarak tatmin edici bir model öne sürülememiştir.

Yapılan çalışmalar 2030 yılında ölümlerin \%90'ının hastanelerde olacağını göstermiştir ${ }^{4}$. $\mathrm{Bu}$ durum birçok hastalı̆̆ın son dönemlerinin hekimler tarafından gözlenmesine ve ölüm iyiliği fenomeninin farklı hastalıklar arasında değişkenlik gösterip göstermediğinin açıklı̆̆a kavuşturulmasında faydalı olacaktır. Bugüne kadar yapılan yayınlarda bu fenomenin ölümden bazen dakikalar, saatler bazen de günler, haftalar öncesinde başladığı belirtilmiştir. Ayrica ölüm iyiliği fenomeninde yaşanan aydınlanmanın bazen sadece hafızanın kısa süre ile geri kazanılması sınırlı kaldığı bazen de hastaların kaybettiği konuşma, motor becerilerinin de geri geldiği belirtilmiştir ${ }^{2}$. Bu örnekler belki de ölüm iyiliği fenomeninin gelecekte yapılacak araştırmalar sonrasında kendi içerisinde alt dallara ayrılacağının habercisidir. Ölüm iyiliği fenomenini daha iyi anlayabilmek için yapılması gereken öncelikle sağlık çalışanlarının bu konuda yeterli bilgi düzeyine sahip olmasını sağlamak, hastanede yatan olgularla ilgili yeterli kayıt tutmak ve bu fenomenin belirtilerinin hastalıklar arasında değişkenlik gösterip göstermediğini gözlemlemektir. Ölüm iyiliği fenomeninin aydınlatılması hastaların son dönemlerinin hastalar ve yakınları için daha huzurlu geçmesini sağlayacak, seyirleri sırasında çıktığ1 hastalıkların tedavisinde yeni yöntemler geliştirilmesine yardımcı olacaktır.

\section{KAYNAKLAR}

1. Nahm M. Terminal lucidity in people with mental illness and other mental disability: an overview and implications for possible explanatory models. J Near Death Stud. 2009;28:87-106.

2. Nahm M, Greyson B, Kelly WE, Haraldsson E. Terminal lucidity: a review and case collection. Arch Gerontol Geriatr. 2012;55:138-42.

3. Fenwick P, Lovelace H, Brayne S. Comfort for dying: Five year retrospective and one year prospective studies of end life experiences. Arch Gerontol Geriatr. 2010;51:173-9.

4. Fenwick P. End of life experiences: phenomena of dying. J Holistic Health. 2011;8:22-6.

5. Nahm M, Greyson B. Terminal lucidity in patients with chronic schizophrenia and dementia. J Nerv Ment Dis. 2009;197:942-4.

6. Turetskaia BE, Romanenko AA. Agonal remission in the terminal stages of schizophrenia. Korsakov J. Neuropathol Psychiatr. 1975;75:559-62.

7. Bennett AE, Cash PT, Hoekstra CS. Artificial fever in general paresis with electroencephalographic studies. Psychiatr Q. 1941;15:750-71.

8. Braslow J. Mental Ills and Bodily Cures: Psychiatric Treatment in the First Half of Twentieth Century. Berkeley, University of California Press, 1997.

9. Shorter E. A History of Psychiatry: From the Era of the Asylum to the Age of Prozac. New York, Wiley, 1997.

10. Palop JJ, Chin J, Mucke L. A network dysfunction perspective on neurodegenerative diseases. Nature. 2006;443:768-73.

11. Savioz A, Leuba G, Vallet PG, Walzer C. Contribution of neural networks to Alzheimer's disease progression. Brain Res Bull. 2009;80:308-14.

12. Happich F. Das Hessische Brüderhaus und seine Anstalten Hephata. Treysa, Hessisches Brüderhaus, 1947.

13. Wittneben W. Erziehung, behandlung und pflege geistesshwacher. Geisteskrankenpflege. 1934;38:14654.

14. Nahm M, Greyson B. The death of Anna Katharina Ehmer: a case study in terminal lucidity. Omega. 2013;68:77-87.

15. Leubuscher R. Wiederkehr des Bewustseins vor dem 
Tode bie einer Blödsinnigen. Medicinische Zeitung von dem Verein für Heilkunde in Pressen 48, 1846.

16. Noyes M. A true account of a beautiful passing Light. 1952;72:65.

17. Osis K. Deathbed Observations by Physicians and
Nurses. New York, Parapsychological Assoc., 1961.

18. Butzke F. Rückblicke auf das klinische Jahr 1938 im Provinzial-Landkran-kenhause der Prowinz Westpreussen bei Schwetz. Magazin für die gesammte Heilkunde. 1840;14:140-71 